\title{
Research on Seismic Performance of an Innovative Upper-Lower Half-Story Precast Shear Wall
}

\author{
Yanyan Sun $\mathbb{D}^{1},{ }^{1}$ Zhenbo Wang $\mathbb{D}{ }^{2}$ and Jing $X u \mathbb{C}^{1}$ \\ ${ }^{1}$ School of Civil Engineering and Architecture, Suqian University, 223800 Suqian, Jiangsu, China \\ ${ }^{2}$ College of Civil Engineering, Nanjing Tech University, 21009 Nanjing, Jiangsu, China \\ Correspondence should be addressed to Yanyan Sun; yanyansun@squ.edu.cn
}

Received 6 February 2021; Revised 1 April 2021; Accepted 30 April 2021; Published 19 May 2021

Academic Editor: Minghui Li

Copyright (c) 2021 Yanyan Sun et al. This is an open access article distributed under the Creative Commons Attribution License, which permits unrestricted use, distribution, and reproduction in any medium, provided the original work is properly cited.

An innovative precast connection (the precast connection installed in the middle of the shear wall) was proposed for the shear wall. To verify the effectiveness of the proposed precast connection, two cast-in-situ shear walls (RCW1 and RCW2) and three precast shear walls (PCW1, PCW2, and PCW3) were manufactured and investigated. The construction joints were inserted in the bottom and the middle for RCW1 and RCW2; and the structural glue horizontal connection, structural glue cogged connection, and cast-in-situ plug grouting connection were utilized for PCW1, PCW2, and PCW3, respectively. The failure mode, loading capacity, ductility, stiffness degradation, and energy dissipation of specimens were analyzed under the horizontal low-frequency cycled loading. Simultaneously, a numerical simulation was carried out on the ABAQUS software, and simulation results were consistent with experimental results. The result showed that the moment-shear failure occurred in all the specimens except PCW1; the bottoms of PCW 2 and PCW 3 were still vulnerable regions. The bearing capacity and the ductility of RCW2 were improved to different degrees by installing the construction joint in the middle of the shear wall. Specifically, the structural glue cogged connection and the cast-in-situ plug grouting connection have no obvious effect on the reduction of bearing capacity but can improve the ductility of the specimen; the stiffness degradation and energy dissipation of RCW1, RCW2, PCW2, and PCW3 were basically the same.

\section{Introduction}

With the rapid increase of environmental awareness in the construction process and the requirements of high-speed urbanization $[1,2]$, the precast concrete structure has been gradually accepted, even in some regions with high seismicity (e.g., Japan, Chile, China, and Zealand). Due to the strong resistance to seismic forces in the planar direction and the transferring ability to the foundation, concrete shear walls have become the preferred structure for high-rise and multistory buildings in recent decades $[3,4]$. In this paper, the seismic performance of innovative upper-lower halfstory precast shear walls under the low-frequency cyclic loading was studied.

The connections of the precast concrete shear wall components were crucial to the mechanical performance of the structure [5], and the vertical connection affects the integrity and energy dissipation of the buildings. Previous studies and analyses have shown that the precast concrete shear walls have the dominant bearing capacity and energy dissipation $[6,7]$. According to the criterion of the American, European, Chinese, and Japanese standards, the performance of some precast concrete shear walls can reach the level of cast-in-situ shear walls $[8,9]$. The joint of components has been primarily studied in previous studies of precast concrete shear walls. Chu et al. [10] conducted six large-scale model experiments under the cyclic lateral loading, including five novel shear wall specimens built with precast concrete hollow mold (PCHM) and a cast-in-situ shear wall. The results indicated that with the width decrease of horizontal cracks, the axial compression ratio increased and the shear span ratio decreased, in which the initial stiffness was significantly strengthened and the slipping deformation was restricted in the bottom. Hamid and 
Mander [11-13] believed that precast hollow wall panel assemblies had excellent seismic performance and proposed a structural damage control design method for the precast hollow wall. Smith et al. [14] compared and analyzed the seismic behavior of the hybrid assembly shear walls and castin-situ shear walls and concluded that the application of the hybrid assembly shear walls in seismic regions was significantly feasible. Zhai et al. [15] manufactured and tested six double-short-limb reinforced concrete precast shear wall specimens (the ceramsite concrete hollow block masonry infilling, concrete integration infilling with a hollow tube, concrete integration infilling with polystyrene plate Sandwich, unfilled shear wall, lightweight partition board infilling, and ceramsite concrete infilling) and simulated the finite element models in the same condition. The results indicated that the integration shear wall and the shear wall with the ceramsite concrete infilling have a better shear bearing capacity, stiffness, energy dissipation, and reliable seismic performance.

The connection of precast shear walls plays an important role in integrity, stability, and energy dissipation. The seismic behaviors of components or structures and the reliability of connection joints have become significant issues in the researches and applications of precast shear walls [16]. Li et al. [7] prepared three T-shaped partly prefabricated reinforced concrete shear walls and one cast-in-situ shear wall and performed experimental tests on the connection of components under the low-frequency loading. The results showed that, compared with the cast-in-situ specimens, the partly prefabricated specimens have excellent energy dissipation, ductility, and stiffness. Xu and Li [17] designed a new type of concrete Sandwich including cast-in-situ concrete and precast concrete and analyzed the seismic performance of the proposed concrete Sandwich experimentally and numerically. The results showed that the stiffness, bearing capacity, and structural damage of the steel connection with aluminum friction plate $(\mathrm{CAF})$ and the precast Sandwich wall with special round steels (SRS) decrease; the energy dissipation and the deformation capacity of the structure increase significantly. $\mathrm{Gu}$ et al. [18] used various vertical rebar lap splice positions and rebar lap lengths at the horizontal assembly joints of the specimens as parameters. And the seismic performances of four precast concrete shear walls and one cast-in-situ concrete shear wall were analyzed. The test results showed that in terms of failure modes, bearing capacity, energy dissipation, and load-lateral drift hysteresis curves of specimens, the precast concrete shear walls have significant seismic behaviors and are comparable to the cast-in-situ shear walls. To investigate the behavior of the Welded Bar Sleeve (WBS) connection, Ling et al. [19] proposed and tested specimens with a new grouted splice connection under the tensile, shear, and flexural loading. They analyzed the load-displacement curves, ultimate capacities, ductility capacities, and some feasibility assessment criteria. The results indicated that the WBS connection can provide sufficient strength at the appropriate bar with the embedded length and the flexural load was the most critical issue for the connection.
The above researches have revealed that the moment at the bottom of the precast concrete shear walls implicitly facilitated the occurrence and development of the horizontal concrete crack under the cyclic loading, while the oblique concrete cracks below the middle of the shear wall were caused by the shear force. As a result, the concrete was crushed and the reinforcement was exposed at the corner of the bottom. To avoid the intricate internal force region, some researchers have changed the connection's position $[16,20]$. $\mathrm{Lu}$ et al. [16] proposed a new type of prefabricated concrete joint for connecting upper and lower members, which has the advantages of convenient installation and material saving. The research results indicated that the connection beam can significantly transfer the lateral loading to the bottom, specifically in squat precast walls. In order to decline the energy dissipation and ductility of precast shear walls under the cyclic loading, Kang et al. [20] designed bonded or unbonded longitudinal rebar with the partially decreased cross-sectional area. The plastic hinge was sufficiently developed in which the reinforcements were partially reduced to prevent the shear slippage and gap opening in the connection.

In general, the bottom of the precast concrete shear wall or construction joint is an extremely feeble region with complex internal forces (such as moment, shear, and axial compression). The optimized connection not only enhances the connection or structural integrity (conformations, materials, and parameters of grout sleeves) but also changes the connection from the bottom to the middle. When the connection is set in the middle of the wall, there are fewer moments, and the damage of the bottom can be effectively restricted to reinforce the structural integrity. Based on the above, an innovative upper-lower half-story precast shear wall was proposed in this paper, including a lower-half-story wall, beam, and upper-half-story wall (as shown in Figure 1). Although the proposed units were difficult to be assembled because they were heavier and larger than common units, there was no construction joint in the bottom of the wall. And the middle region where the connection was installed bore smaller loads than the bottom region. Therefore, the bearing capacity, energy dissipation, and ductility would be enhanced. Furthermore, as the assembled unit was used to avoid the cast-in-situ of the beam during assembly, the assembly rate and construction efficiency of structures were improved. In this test, three modes of connections were employed, including the structural glue horizontal connection, the structural glue cogged connection, and the castin-situ plug grouting connection. Besides, the left-right sides of precast concrete shear walls were embedded in hidden columns with the cast-in-situ reinforced concrete. Both the seismic performances and finite element analysis were conducted in this investigation.

\section{Experimental Investigation}

2.1. Description of Specimens. Due to the limited laboratory conditions, five half-scale specimens marked as RCW1, RCW2, PCW1, PCW2, and PCW3 were prepared in this 


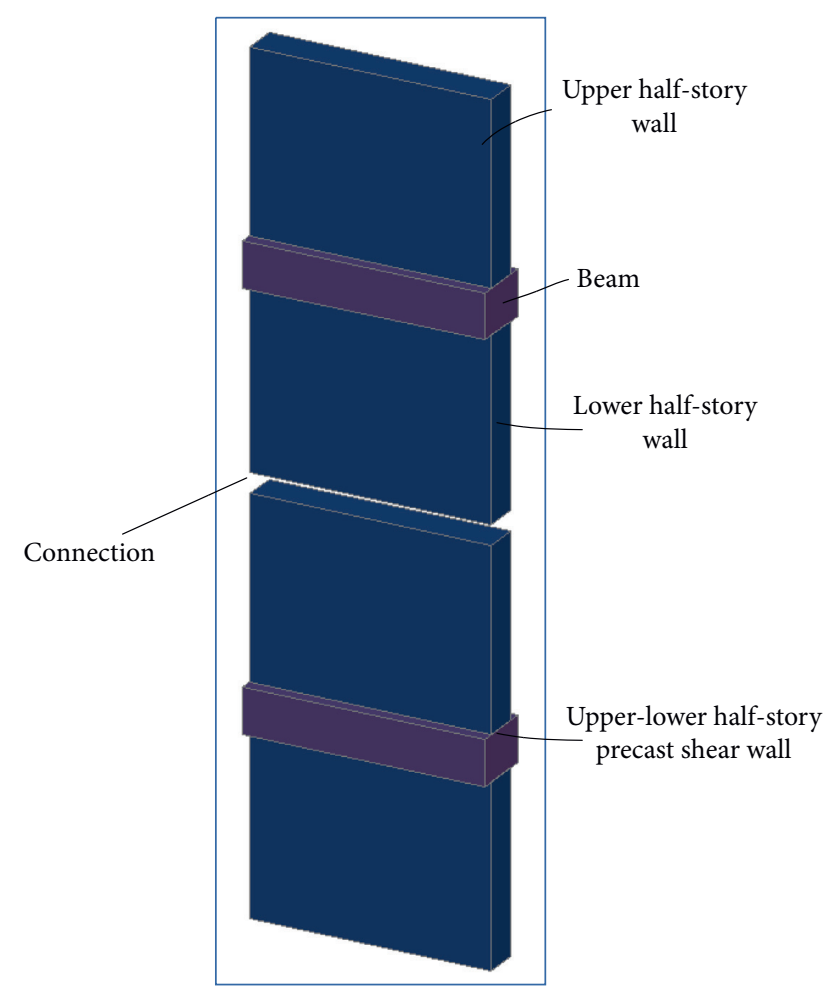

FIGURE 1: Upper and lower-half-story assembly units.

paper. For simplicity, the RCWs denoted cast-in-situ concrete walls and the PCWs denoted precast concrete walls. The dimensionless term of the half-scale sample was of great significance for further research in this field. For RCWs, the position of the construction joint was different: the construction joint of RCW1 was installed in the bottom and that of RCW 2 was in the middle. As the specimen was the single layer, the upper-half wall and the lower-half wall were designed and manufactured, respectively. The upper-half wall and load beam were united into a precast component while the lower-half wall and the foundation were combined as the other one. Cast-in-situ hidden columns on both leftright sides were inserted in PCWs to guarantee the integrity and stability of connections [10]. Figure 2 shows the specific forms of the specimens in which the reinforcement of all specimens was the same [16]. The connection types designed in this study were as follows:

(1) The structural glue flat connection: The structural glue associated with the upper and lower precast components was used. This connection was utilized for PCW1. It was noted that there was no reinforcing rebar through the structural glue layer.

(2) The structural glue cogged connection: Cogged connection was used. This connection was utilized for PCW2, and the only difference with the PCW1 was the cogged connection.

(3) The cast-in-situ plug grouting connection: The upper and lower components were arranged with corrugated pipes at the corresponding positions to supplement the grouting holes. This connection was utilized for PCW3.

2.2. Dimensions and Steel Reinforcement of Specimens. Figure 2 shows the details of all specimens. The grade of concrete and cement grout was C30 and 425R, and the thickness of the concrete cover was $15 \mathrm{~mm}$. The reinforcement of the HRB400 strength grade, referred to as "C," was uniquely utilized in all specimens. Firstly, the longitudinal rebar of the beam with the dimension of $800 \mathrm{~mm} \times 200 \mathrm{~mm} \times 200 \mathrm{~mm}$ was $4 \mathrm{C} 10$, and the stirrup rebar was C6@100. Secondly, the dimension of shear walls was $800 \mathrm{~mm} \times 1100 \mathrm{~mm} \times 120 \mathrm{~mm}$, in which the horizontal rebar and the vertical rebar were C6@100. The arrangement of longitudinal rebar and stirrup rebar in hidden columns was 4C10 and C6@100, respectively. Thirdly, the 8C16 and C10@ 100 were the arrangements of rebar in the foundation reinforcement. Furthermore, the diameter and the length of corrugated pipes of PCW3 were $80 \mathrm{~mm}$ and $500 \mathrm{~mm}$, respectively, in which the length in the upper or lower part was $250 \mathrm{~mm}$ and the gap between corrugated pipes was $40 \mathrm{~mm}$. And a $480 \mathrm{~mm}$ length rebar was fixed in the center of each pipe, which was not connected with any internal reinforcing rebars.

2.3. Material Properties. During the manufacture of the specimens, the concrete of specimens was poured into three batches, and all of them were cured under the same conditions. According to the Standard for Test Methods of Mechanical Properties on Ordinary Concrete [21], three $150 \mathrm{~mm}$ concrete-edged cube specimens in each group were used to detect the compressive strength of the concrete cube. The compressive strength of concrete cubes is shown in Table 1. Besides, three steel rebar specimens were tested to obtain the yielding strength, ultimate strength, and elastic modulus, as shown in Table 2.

2.4. Loading and Instrumentation. As shown in Figure 3, several bolts passed through the anchorage holes of specimens to ensure that the foundation was fixed on the laboratory ground. The specimens were subjected to horizontal cyclic loading and constant vertical compressive loading by a $250 \mathrm{kN}$ MTS electrohydraulic servo loading system and a $100 \mathrm{kN}$ hydraulic Jack. The axial compressive ratio was set as 0.2 . Figure 4 shows the loading program, and the incremental quantity of loading force was set as $10 \mathrm{kN}$. The reciprocation of force loading was only one time in each grade before yielding. Once the longitudinal rebar stress in the bottom of the shear wall reached yielding strength, the displacement control was used, instead of forced control. Displacement of each grade was progressively increased by $5 \mathrm{~mm}$ initiated on the yielding displacement. Under the loading condition of displacement control, each level of loading was cycled once. When the bearing capacity of the specimen dropped to $85 \%$ of peak load, or a significant slippage occurred (that is, the specimen cannot bear the 


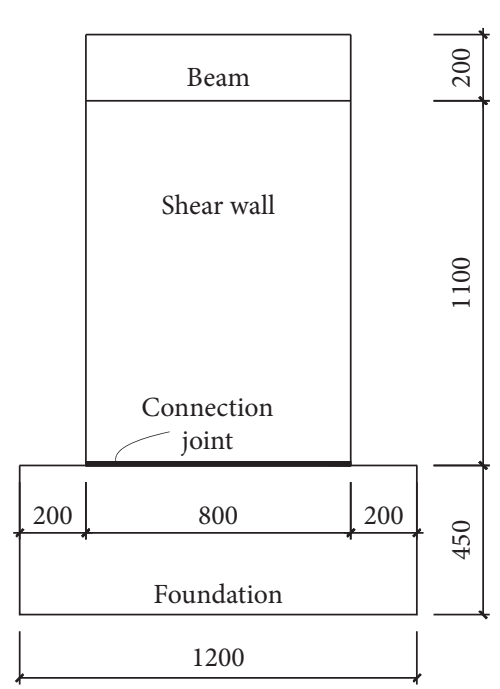

(a)

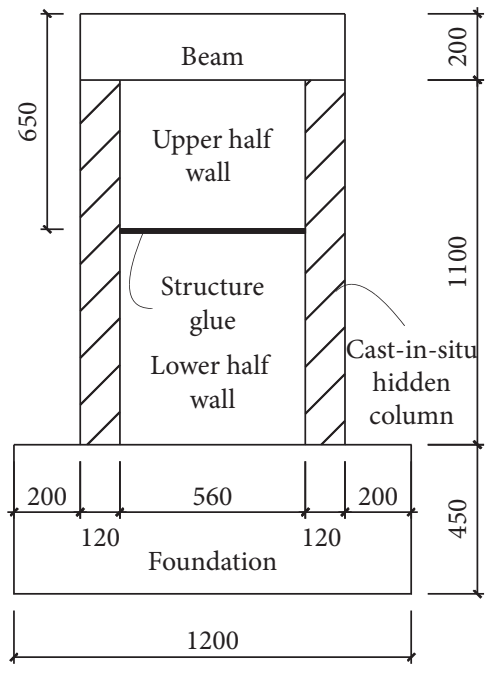

(c)

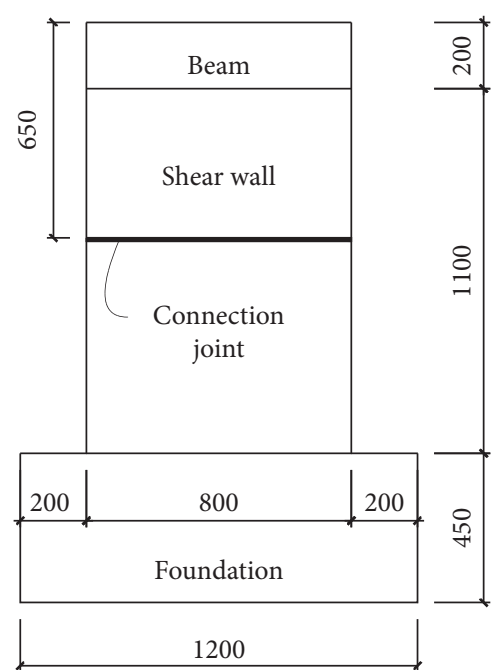

(b)

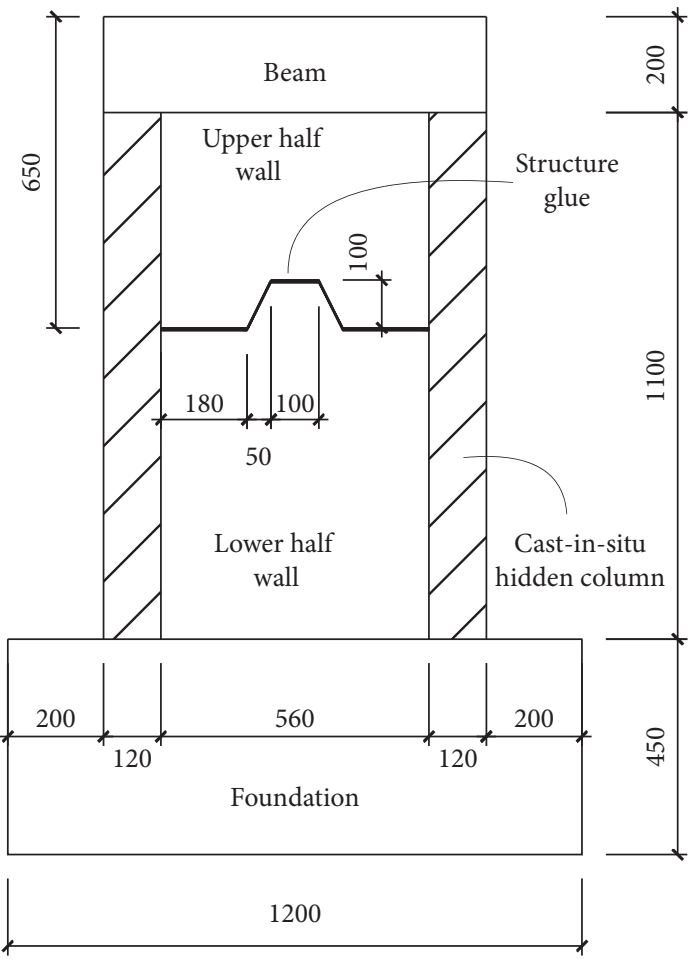

(d)

Figure 2: Continued. 


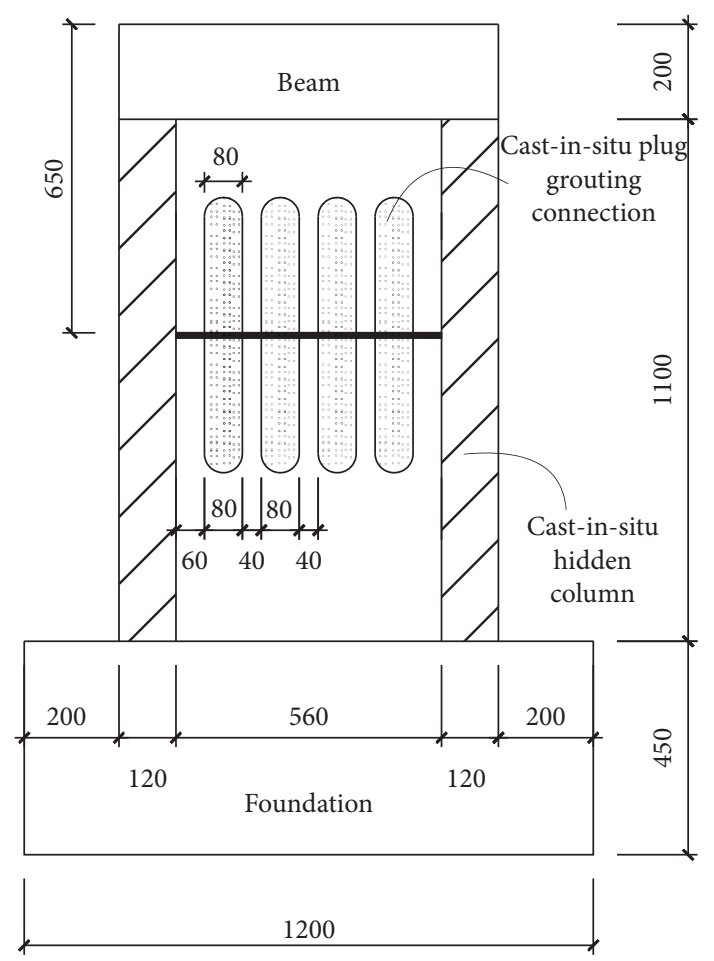

(e)
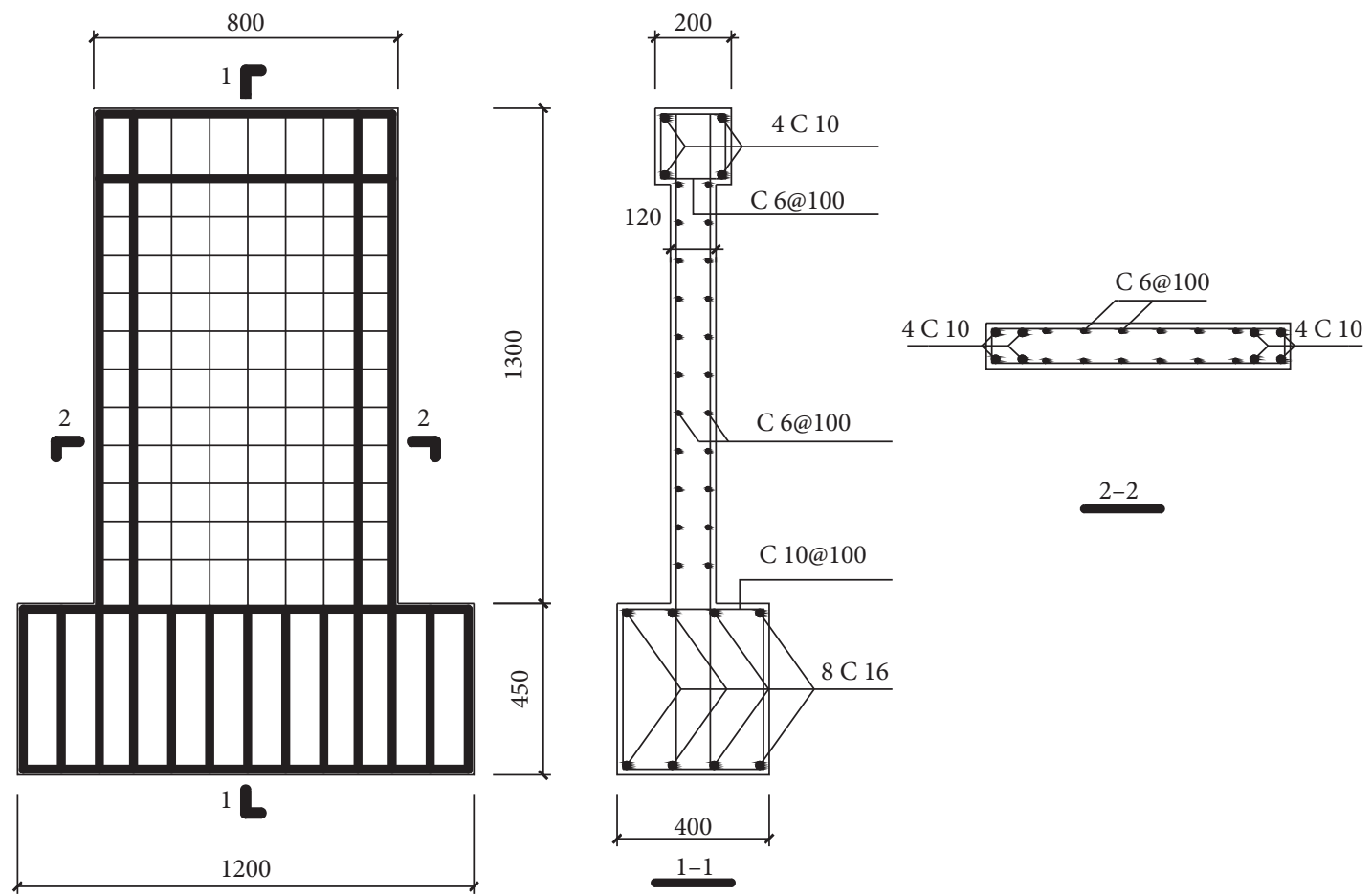

(f)

FIGURE 2: Dimensions and reinforcement details of specimens (Figure 2 is reproduced from Lu et al. [21]). (a) RCW1. (b) RCW2. (c) PCW1. (d) PCW2. (e) PCW3. (f) Reinforcement details of all specimens. 
TABle 1: Strength of concrete (unit: MPa).

\begin{tabular}{lcccc}
\hline Batch & $1 \#$ & $2 \#$ & $3 \#$ & Average \\
\hline 1st & 34.6 & 33.5 & 36.1 & 34.7 \\
2nd & 31.3 & 32.7 & 39.2 & 34.4 \\
3th & 38.9 & 36.5 & 40.2 & 38.5 \\
\hline
\end{tabular}

TABLE 2: Representatives of rebar performance.

\begin{tabular}{lcccc}
\hline$D(\mathrm{~mm})$ & $f_{y}(\mathrm{MPa})$ & $f_{u}(\mathrm{MPa})$ & $\delta(\%)$ & $E(\mathrm{MPa})$ \\
\hline 6 & 469.2 & 577.4 & 26 & $1.73 \times 10^{5}$ \\
10 & 495.1 & 586.8 & 26 & $1.84 \times 10^{5}$ \\
16 & 497.2 & 615.5 & 25 & $1.91 \times 10^{5}$ \\
\hline
\end{tabular}
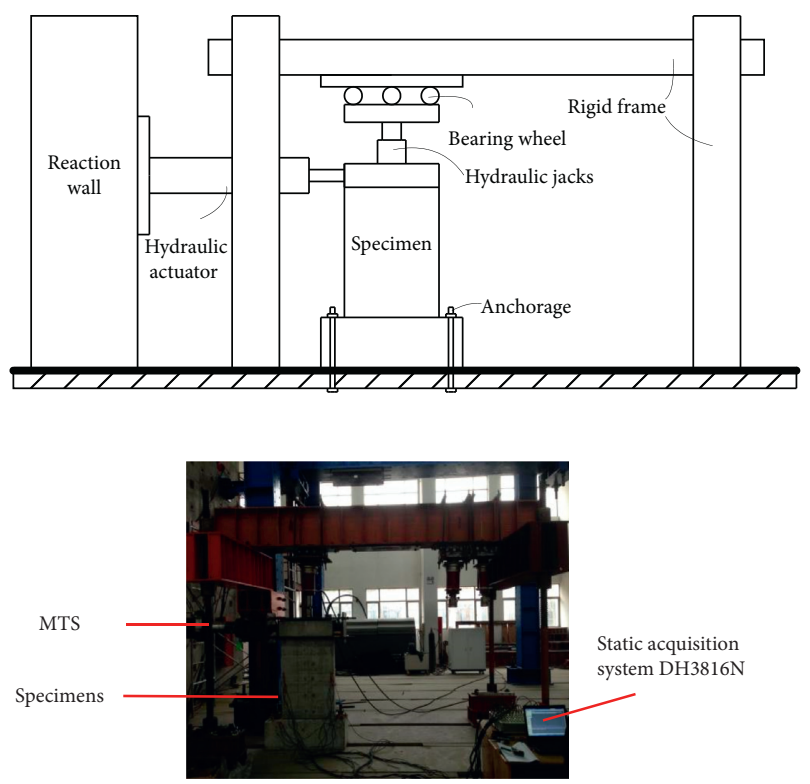

Figure 3: Pseudo-static test loading device for shear walls.

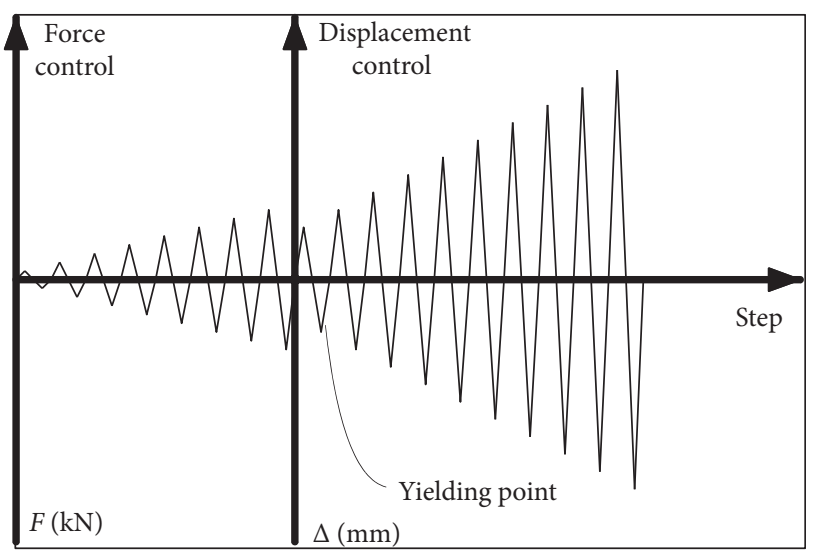

FIGURE 4: Loading program.

horizontal or vertical loading), then the loading was terminated [22].

In addition, the longitudinal and stirrup rebar, in both left-right hidden columns at the middle and the bottom of shear walls, were glued with a resistance strain gauge to observe their strain. The static acquisition system DH3816N was linked to the strain gauge to monitor and record the experimental data in real time (Figure 3).

\section{Experimental Result and Discussion}

3.1. Experimental Procedures and Phenomenon. During the whole experiment (including forced control and displacement control), the "+" indicated that the hydraulic actuator was in a pushing condition, while the "-" indicated that the hydraulic actuator was in a pulling condition. It should be noted that pushing was generally before pulling in each loading grand. As shown in Figure 2, the experimental surfaces were generally divided into the front surface, back surface, and lateral surface.

Due to the bending moment, when the vertex horizontal load reached $-78 \mathrm{kN}$ in the forced control, a first horizontal crack of RCW1 appeared faintly on the lateral surface $300 \mathrm{~mm}$ away above the bottom of the shear wall. When the horizontal load was $-95 \mathrm{kN}$, another horizontal crack was generated on the lateral surface $130 \mathrm{~mm}$ away from the bottom. With the increase of the load, the number of horizontal cracks at the tensile side of RCW1 gradually increased, and cracks were also generated near the middle of the specimen. The earlier horizontal cracks continued to extend and had a downward trend of oblique cracks. When the specimen RCW1 yielded, most of the horizontal cracks were developed into bending-shear diagonal cracks, but the diagonal cracks were not penetrated.

As the vertex horizontal displacement reached $\pm 20 \mathrm{~mm}$ under the displacement control, the number of diagonal cracks initiated from lateral sides progressed into the $X$ shaped distribution. When the displacement was $25 \mathrm{~mm}$, the construction joint at the root of the tension side was pulled apart, resulting in a long horizontal crack, and the surface of the concrete at the root of the compression side was slightly peeled off. During the remaining experiment, a part of diagonal cracks expanded to the bottom of specimens, and the width of the construction joint in the bottom was gradually widened. Meanwhile, the concrete in the compression region was crushed with cracking noise. The ultimate damage revealed that the cracks at the bottom were pulled apart, and the concrete under the compression was crushed. Figure 5 shows the crack distribution, the ultimate damage, and the bottom deformation of all specimens.

The failure modes of RCW2 and RCW1 were very similar, except the fact that the horizontal and oblique cracks of RCW2 were relatively dispersed. The bottom of the RCW2 was not pulled away, and almost no cracks appeared at the construction joint location (i.e., the middle part of the specimen). In general, the bottom of shear walls was the weakest region bearing the constant shear force and maximum bending moment; in particular, when the region was installed as connecting node, it was most prone to be damaged. Hence, RCW2 had more diagonal cracks than RCW 1 because the construction joints of RCW2 were installed in the middle position, and the internal force was relatively small. It indicated that when the construction joint region was changed from the bottom to middle, the integrity 

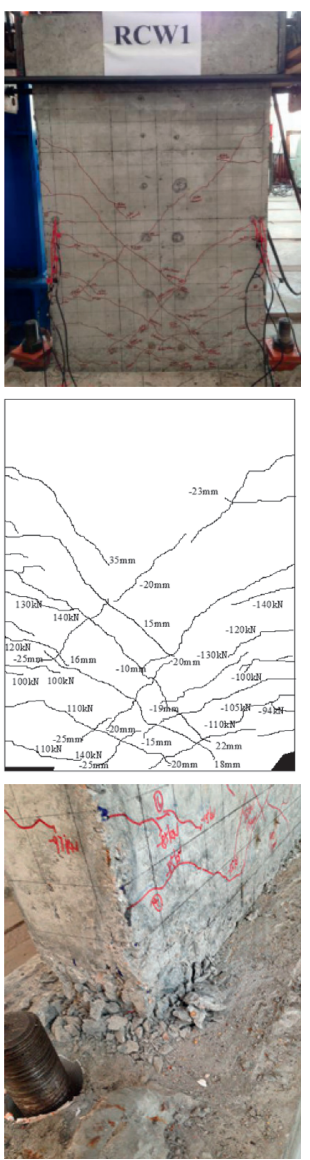

(a)
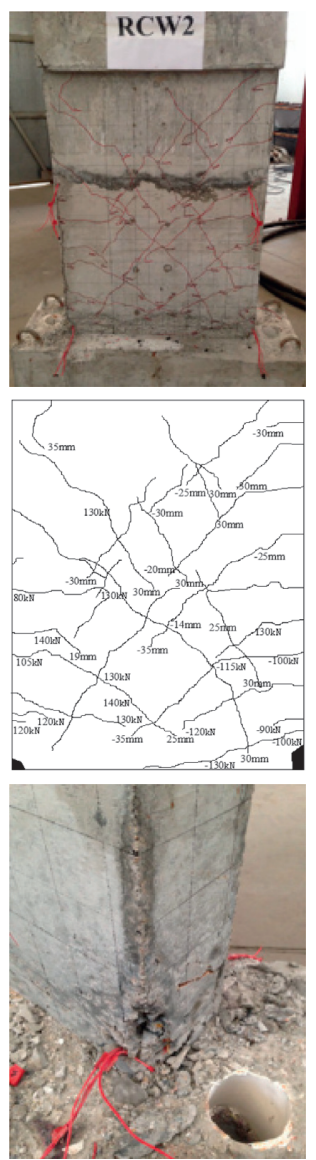

(b)
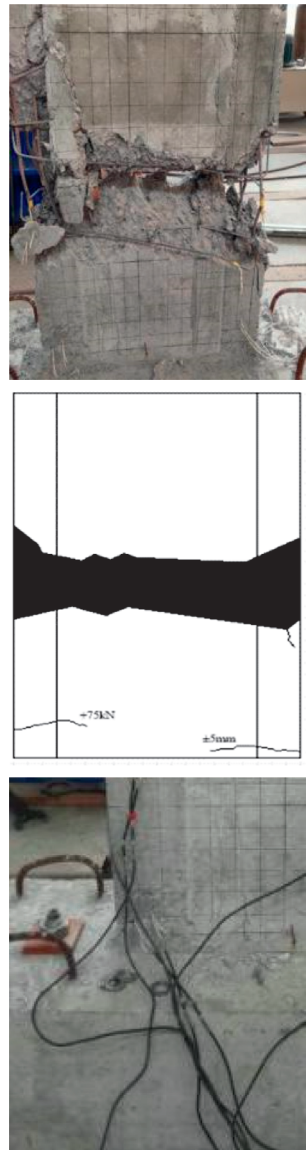

(c)
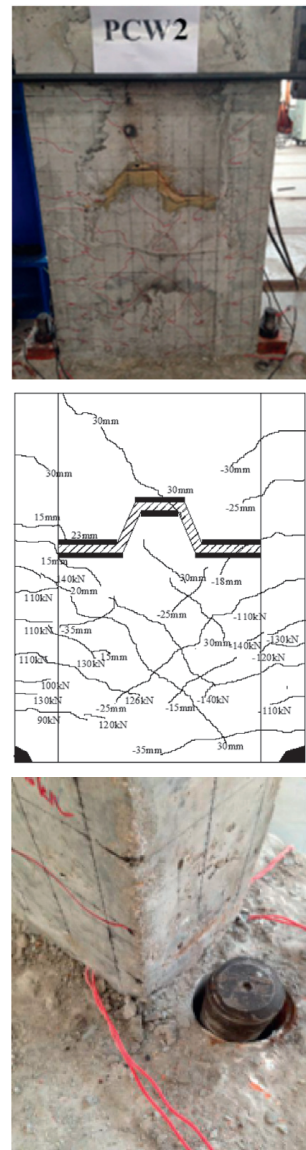

(d)
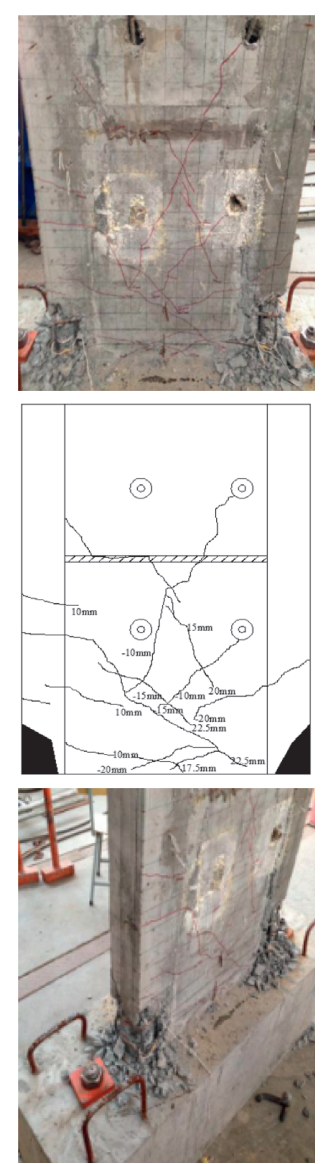

(e)

Figure 5: The final damage of specimens. (a) RCW1. (b) RCW2. (c) PCW1. (d) PCW2. (e) PCW3.

of the bottom region was enhanced, compared with the traditional shear wall. As a result, the damage of specimens can be relieved, specifically, the damage at the bottom of shear walls.

The performance of the PCW1 (using structural glue combining the upper and lower precast components) was significantly different from that of other specimens. When the horizontal force reached $72 \mathrm{kN}$ in the forced control, a moment crack appeared on the lateral surface $70 \mathrm{~mm}$ away above the bottom. The new cracks were no longer generated and developed in the force control. As the displacement reached $\pm 10 \mathrm{~mm}$, the structural glue was rapidly split in accompany with cracking noise at the horizontal interface. With the gradual increase of the vertex horizontal displacement, the width and length of cracks were enlarged. When the displacement was $22.5 \mathrm{~mm}$, the obvious slippage failure occurred at the joint of the specimen.

The failure mode of the PCW2 (assembling with the cogged connection in terms of structural glue) was basically identical to that of the RCW2. However, a few thin cracks were only generated around the connection position, and the stability of the specimen was maintained by the structural glue during the entire experimental process. The failure mode of PCW3 (with the cast-in-situ plug grouting connection) was proximate to that of RCW1. It is observed that the crack distribution in the lower-half shear wall of PCW3 was sparser than that of RCW1. The connection joints of PCW2 and PCW3 were almost integrated throughout the test. Above all, the bottom was still the weakest region and the failure modes were not changed with the change of connection position.

3.2. Hysteretic Curves. Figure 6 shows the load-displacement hysteretic curves of all specimens. The hysteretic curves were straight before yielding, indicating that the specimens were in the elastic stage with few residual deformations. Under the action of displacement control, the hysteretic curves gradually became full, and the area formed by the closed curve gradually increased. It indicated that the capacity of energy dissipation was enhanced, and the curves were in an inverse $S$ shape. There was little difference between the curve shape, the peak value, and the ultimate value of RCW1, RCW2, PCW2, and PCW3. Although the shape of the hysteretic curve of PCW1 was similar to that of other specimens, the yielding load, the peak load, and the ultimate load were obviously lower. Because there was no longitudinal rebar connection in PCW1, the horizontal structural glue connection cannot bear the shear force, and the bearing capacity was almost borne by the hidden column under the 

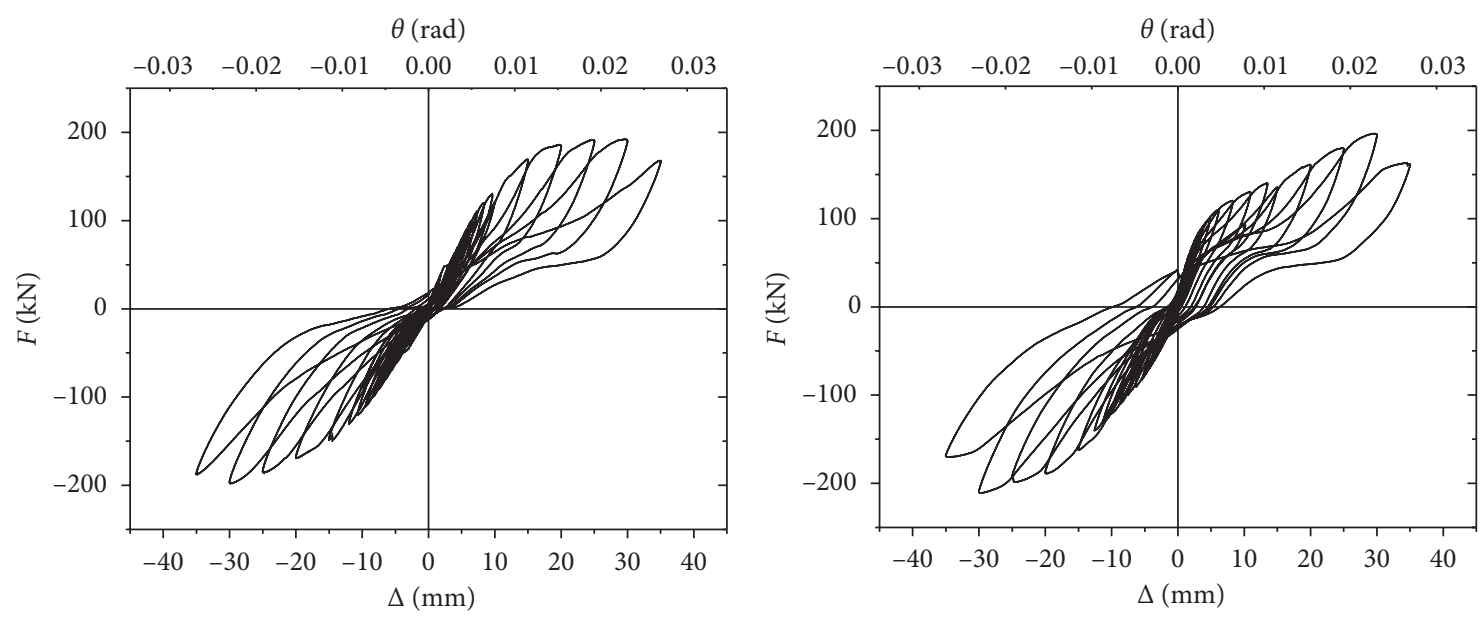

- RCW1

(a)

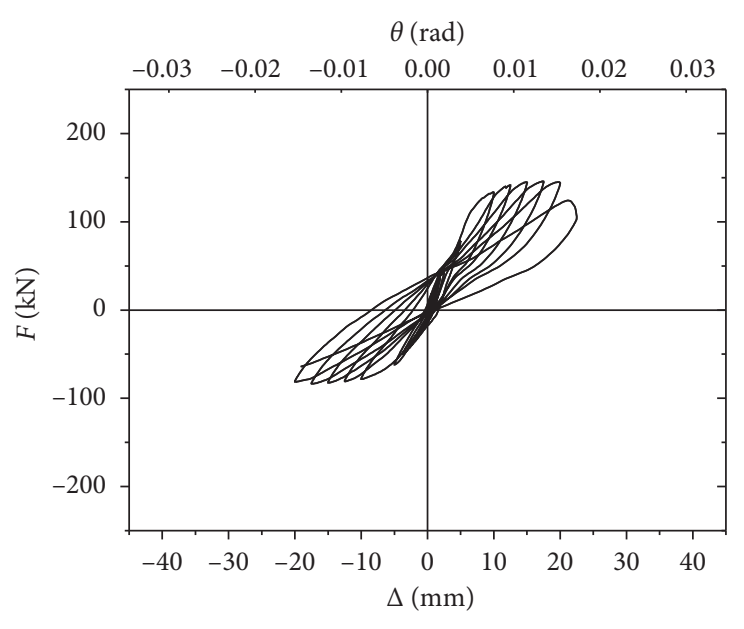

(b)

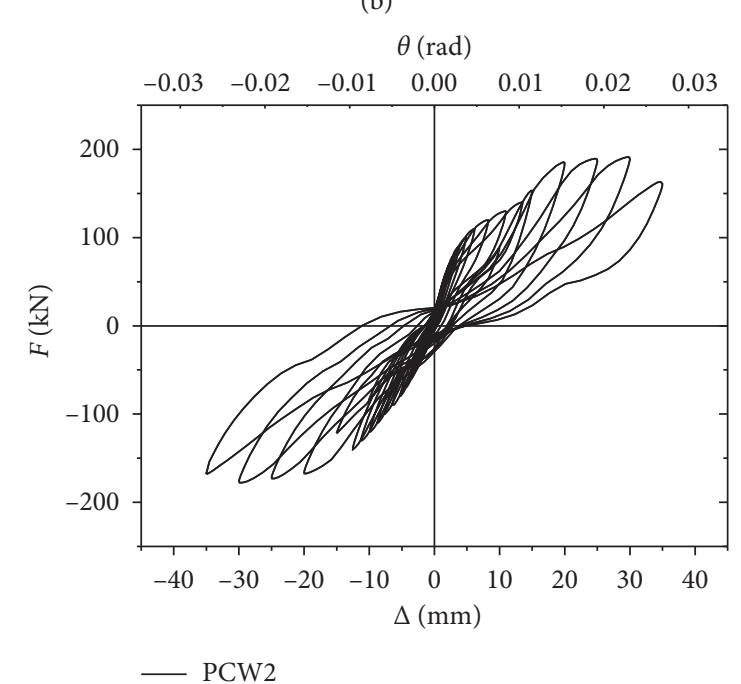

(c)
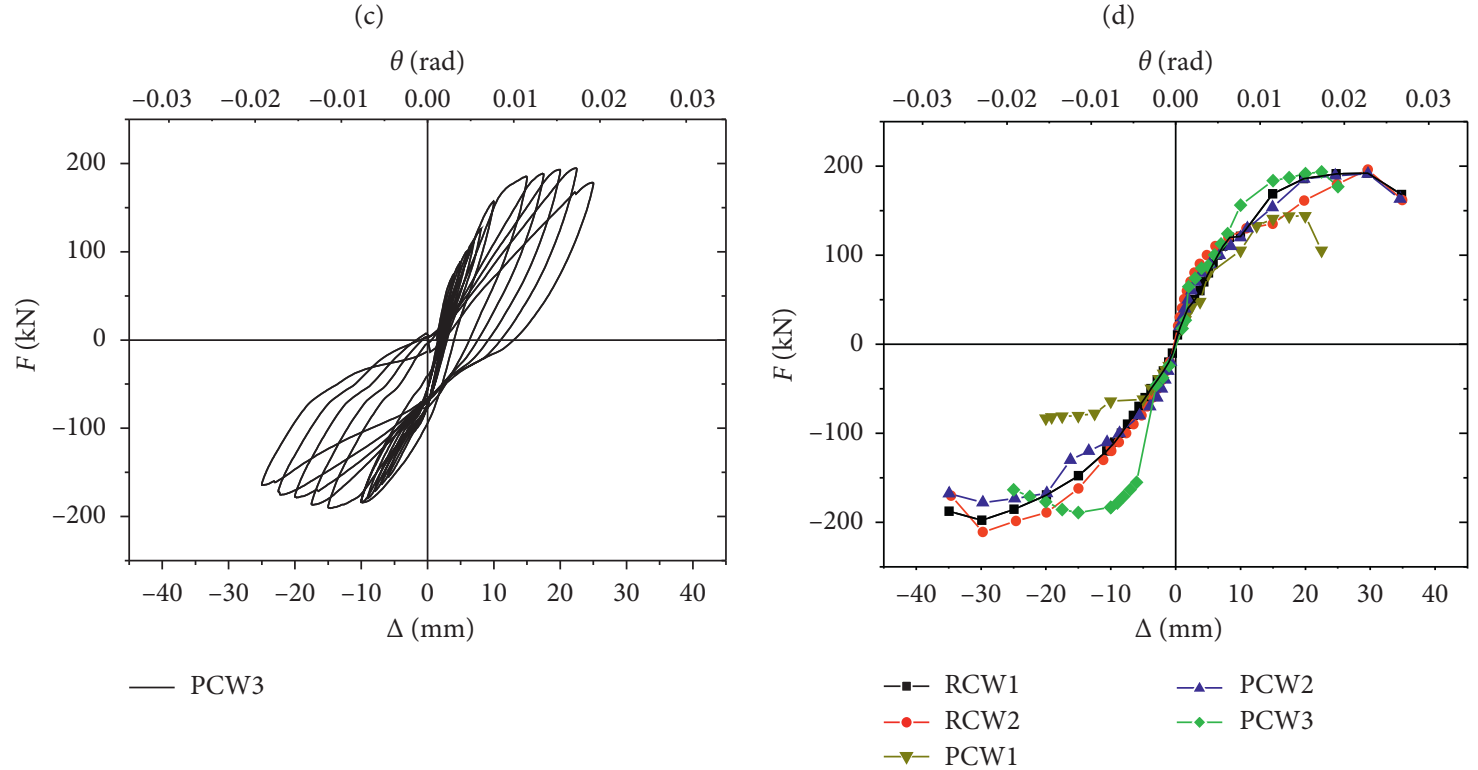

(e)

(f)

FIGURE 6: Hysteresis curves and skeleton curves of the specimens. (a) Hysteresis curve of RCW1. (b) Hysteresis curve of RCW2. (c) Hysteresis curve of PCW1. (d) Hysteresis curve of PCW2. (e) Hysteresis curve of PCW3. (f) Skeleton curves of the specimens. 
displacement control. Therefore, compared with other specimens, the load-bearing capacity of the specimen PCW1 was smaller; when PCW1 was damaged, its ultimate displacement was the smallest with the serious damage of the hidden column. Therefore, the position change of the construction joint and the two types of connection of precast concrete shear walls hardly affected the hysteretic curves of specimens.

3.3. Skeleton Curves. Figure 6(f) shows the skeleton curves of specimens. Each skeleton curve had an obvious inflection point (i.e., the yielding of specimens), after which the slope of the curve dropped rapidly. Except for PCW1, skeleton curves were basically the same. For the PCW1, the horizontal connection with structural glue was adopted, and the longitudinal rebar of each component cannot be combined; then, the shear capability was hardly provided, and both left and right hidden columns of PCW 1 did bear the whole shear force essentially. Consequently, the skeleton curve of PCW1 was definitely lower in yielding load capability and peak load capability.

The skeleton curves of specimens can be divided into three stages: the elastic stage, elastic-plastic stage, and descent stage. In the elastic stage, the initial stiffness of RCW2, PCW2, and PCW3 was slightly larger than that of RCW1. The reason was that the bottoms of RCW2, PCW2, and PCW3 were manufactured in integrity instead of construction joint, and crack distribution around the bottom of RCW2, PCW2, and PCW3 was sparser than that of RCW1. It indicated that installing a connection in the middle of the shear wall can reduce the damage of the bottom and make the specimen more integrated before yielding.

3.4. Characteristic Loads and Ductility. Table 3 shows several representative parameters of the experiments. The $\theta_{y}, \theta_{p}$, and $\theta_{u}$ were instance interstory drift ratios corresponding to $F_{y}$ (yielding load), $F_{p}$ (peak load), and $F_{u}$ (ultimate load), respectively. The yield displacement was defined as the smaller value between the displacement of the longitudinal rebar at the bottom of the specimen and the yield displacement calculated by the energy method. The ultimate displacement was recorded when the bearing load declined at $85 \%$ of the peak load [23]. In addition, $\mu_{\Delta}$ was defined as the displacement ductility ratio. Since the skeleton curves were asymmetric, the equation of $\mu_{\Delta}$ was calculated as follows [24]:

$$
\mu_{\Delta}=\frac{\theta_{+\mu}+\theta_{-\mu}}{\theta_{+y}+\theta_{-y}} .
$$

The characteristic loads and displacements of RCW2 and RCW1 were basically the same, but the ductility of RCW2 was slightly larger than that of RCW1. The reason was that the yielding displacement of RCW2 was slightly smaller than that of RCW1, due to the larger initial stiffness of RCW2. The PCW1 had significantly lower loads and displacement in every feature point. Thus, the specimen using the horizontal connection with structural glue in the middle of the shear wall was at risk and hardly met the requirement of the criteria $[25,26]$.

In contrast with RCW $1, F_{y}, F_{p}$, and $F_{u}$ of PCW2, respectively, decreased by $1.37 \%, 5.3 \%$, and $5.3 \%$, while the ductility of PCW2 increased by $9.6 \%$. Similarly, compared with RCW $1, F_{y}, F_{p}$, and $F_{u}$ of PCW3 were reduced by $5 \%$, $5.1 \%$, and $1.2 \%$, but the ductility of PCW3 was increased by $6.8 \%$. And these results of PCW3 were similar to those of PCW2. Namely, the characteristic loads of PCW2 and PCW3 were slightly smaller than or similar to those of RCW1, but the ductility of PCW2 and PCW3 increased. Considering the calculation formula of ductility, it was noted that $\theta_{y}$ of PCW2 was slightly smaller than that of RCW1, and $\theta_{\mu}$ was extremely identical with RCW1 due to the initial stiffness. Not only were the precast components of PCW3 cast-in-situ plug grouting, but also the concealed columns were cast-in-situ. As a result, PCW3 was more integrated and ductile than other specimens. The $\theta_{y}, \theta_{p}$, and $\theta_{u}$ of PCW3 were obviously smaller than those of RCW1 and RCW2, as shown in skeleton curves under the pulling conditions. It indicated that the connection in the middle can effectively prevent the crack initiation and development at the bottom (the weakest region of the shear wall). Hence, the stiffness of PCW3 was increased. On the other hand, the bearing loading capacity and the shear capacity of connections in precast components were slightly smaller than those of the cast-in-situ connections. If the connections are installed in the middle of the wall to apply sufficient bearing shear capacity, precast shear walls of PCW1 and PCW2 can have the expected performance.

The characteristic loads and the feature displacement in backward loading conditions were slightly smaller than those in the forward loading conditions after yielding. The integration of precast specimens, installed by cogged connection with structural glue and plug grouting connection, was definitely inferior to the cast-in-situ specimen. Therefore, the residual deformation of the precast shear wall was much more than that of the cast-in-situ walls, and the Bauschinger effect was enlarged at the connection of precast specimens.

3.5. Stiffness Degradation. With the increase of loading displacement, the stiffness of the specimen decreased gradually and the damage continued to accumulate. The secant stiffness, namely, the implied the maximum bearing capacity under the $i$ th displacement stage, was utilized in this paper. Considering the asymmetry of hysteretic curves between the forward and backward loading conditions, the equivalent secant stiffness can be calculated as follows:

$$
k_{i}=\frac{\left|F_{+i}\right|+\left|F_{-i}\right|}{\left|\Delta_{+i}\right|+\left|\Delta_{-i}\right|},
$$

where $F_{i}$ and $\Delta_{i}$ are the peak load and the peak displacement at $i$ th displacement stage, respectively. The positive sign indicated the forward loading, while the negative sign indicated the reverse loading.

Figure 7 shows the relationship between secant stiffness and displacement. The equivalent stiffness declined with the 
TABLE 3: Characteristic loads and displacements of specimens.

\begin{tabular}{|c|c|c|c|c|c|c|c|c|}
\hline \multicolumn{2}{|c|}{ Number } & $F_{y}(\mathrm{kN})$ & $\theta_{y}(\%)$ & $F_{p}(\mathrm{kN})$ & $\theta_{P}(\%)$ & $F_{\mu}(\mathrm{kN})$ & $\theta_{u}(\%)$ & $\mu_{\Delta}$ \\
\hline \multirow{4}{*}{ RCW1 } & + & 168.8 & 1.15 & 192.1 & 2.28 & 163.3 & 2.68 & \\
\hline & - & -164.8 & -1.44 & -197.8 & -2.29 & -168.1 & -2.68 & 2.07 \\
\hline & Average & 166.8 & 1.29 & 195 & 2.28 & 165.7 & 2.68 & \\
\hline & + & 170.1 & 1.06 & 195.9 & 2.31 & 166.5 & 2.62 & \\
\hline \multirow[t]{3}{*}{ RCW2 } & - & -171.6 & -1.27 & -201.6 & -2.28 & -170.2 & -2.68 & 2.27 \\
\hline & Average & 170.9 & 1.17 & 198.8 & 2.30 & 168.4 & 2.65 & \\
\hline & + & 78.3 & 0.97 & 144.4 & 1.53 & 122.7 & 1.65 & \\
\hline \multirow[t]{3}{*}{ PCW1 } & - & -61.3 & -1.34 & -81.3 & -1.51 & -69.1 & -1.45 & 1.34 \\
\hline & Average & 69.8 & 1.15 & 112.9 & 1.52 & 95.9 & 1.55 & \\
\hline & + & 163.6 & 1.15 & 191.3 & 2.28 & 162.4 & 2.66 & \\
\hline \multirow[t]{3}{*}{ PCW2 } & - & -165.4 & -1.17 & -177.8 & -2.28 & -151.3 & -2.68 & 2.31 \\
\hline & Average & 164.5 & 1.16 & 184.6 & 2.28 & 156.9 & 2.68 & \\
\hline & + & 156.1 & 0.92 & 194.6 & 1.72 & 178.3 & 1.91 & \\
\hline \multirow[t]{2}{*}{ PCW3 } & - & -160.7 & -0.78 & -175.3 & -1.70 & -149 & -1.87 & 2.21 \\
\hline & Average & 158.4 & 0.85 & 185 & 1.71 & 163.7 & 1.89 & \\
\hline
\end{tabular}

increase of displacement [27]. Before yielding, the stiffness of RCW2 and PCW3 was slightly higher, and the declining ratio of RCW2 and PCW3 was smaller than that of RCW1. This was caused by the connection position. For RCW2 and PCW3, connection joints were located in the middle of the specimen, instead of the bottom. Therefore, the initial stiffness of RCW2 and PCW3 was larger and the damage at the bottom was smaller. Owing to the initial flaw of PCW2 in cogged connecting fissures, the stiffness degradation rate was not only faster than that of RCW2 and PCW3 under the cyclic loading but also faster than that of RCW1 after the displacement reached $5 \mathrm{~mm}$. The stiffness and the declining ratio of PCW1 were the lowest and largest of all specimens as illustrated above. Interestingly, the curves of RCW2 and PCW2 were basically the same as those of the RCW1 after yielding, which indicated that the cogged connection with structural glue had stable static performance and application prospect.

3.6. Energy Dissipation. As an important index affecting the seismic performance of the specimens, energy dissipation can be calculated by the area of the enclosed loading-displacement hysteretic loop in each cycle. The larger the area, the better the energy dissipation of specimens.

As shown in Figure 8, the energy dissipation of specimens was basically the same before the displacement reached $10 \mathrm{~mm}$. Not only could the cast-in-situ plug grouting connection of PCW3 bear the shear and the moment, but also the left-right hidden columns provided higher integrity in contrast with RCWs. Therefore, the energy dissipation of PCW3 increased more significantly than that of other specimens after yielding. After the generation of small cracks, the PCW1 specimen with horizontal structural glue connection was unable to withstand the shear force and bending moment due to the lack of vertical reinforcement connection. In the displacement control stage, the energy dissipation of PCW1 was mainly provided by the left and right hidden columns of the specimen. As a result, when the position reached $22.5 \mathrm{~mm}$, the PCW1 specimen suffered slippage failure, and the energy dissipation suddenly

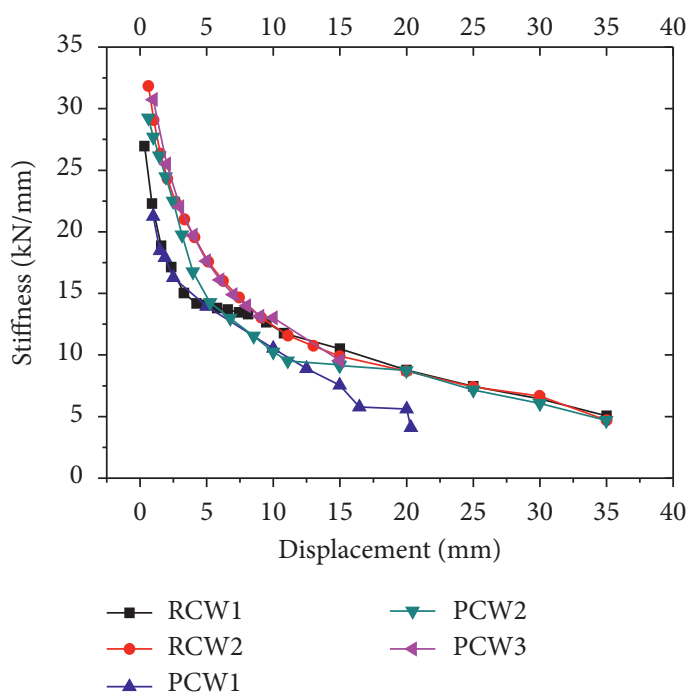

Figure 7: Stiffness degradation of specimens (Figure 7 is reproduced from Li et al. [27]).

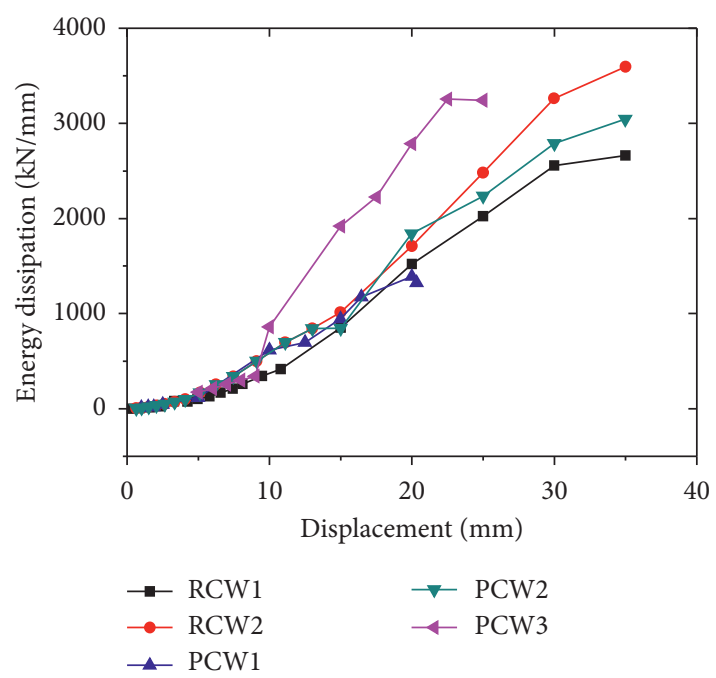

Figure 8: Energy dissipation of specimens. 
stopped. Although the hidden columns were adopted in PCW2, the longitudinal rebars were not connected in the structural glue cogged connection. The energy dissipation was almost provided by the hidden columns. Thus, the energy dissipation capacity of PCW2 was smaller than that of RCW2. Simultaneously, as the connection was changed from the bottom to the middle, there was no connection in the weak region that can supply more energy dissipation capacity. The energy dissipation capacity of PCW2 was higher than that of RCW1. In general, the RCW1, RCW2, and PCW2 were essentially the same in the energy dissipation under the same displacement, and the energy dissipation capacity was decreased in an order of RCW2 $>$ PCW2 $>$ RCW1.

3.7. The Strain of Reinforcement in Hiding Columns. Figure 9 shows the strain of reinforcement in hiding columns of all specimens. As illustrated above, when the strain of reinforcement reached 2200, the specimens were in the elastic-plastic stage. As the PCW1 was split into two pieces, the strains of vertical reinforcement were yielded, which was evidently different from the other specimens.

The growth ratio of vertical reinforcement in the bottom of RCW1 was gentle before yielding and then increased rapidly after yielding. However, the vertical reinforcement in the middle did not reach the yielding in the entire process. The same phenomenon was observed in RCW2, PCW2, and PCW3, in which the strain of vertical reinforcement had no obvious difference between cast-in-place and precast specimens. It indicated that the change of the construction joint and two connections of PCW2 and PCW3 did not affect the strain of reinforcement, which was consistent with the experimental outcomes.

\section{Numerical Simulation}

The finite element models of PCW2 and PCW3 were established and analyzed by the commercial program ABAQUS. In the comparison of their skeleton curves and characteristic loads with the experimental results, the accuracy of the finite element simulation results was verified.

4.1. Constitutive Relationship. In this paper, the concrete damaged plasticity model was adopted, and the difference of tension and compression, and the convergence in strength and stiffness were considered [28]. The constitutive relationship of concrete under uniaxial tension and compression in the model is shown in Figure 10 [29]. The full curve model was used to calculate the steel bar model, in which the yielding strength, the Poisson ratio $\mu$, and the elastic modulus $E$ were $420 \mathrm{MPa}, 0.3$, and $2.0 \times 10^{5} \mathrm{MPa}$, respectively. The constitutive relationship of the steel bar model was calculated as follows:

$$
\sigma= \begin{cases}E_{s} \varepsilon, & \varepsilon \leq \varepsilon_{y}, \\ f_{y}, & \varepsilon_{y}<\varepsilon \leq k_{1} \varepsilon_{y}, \\ k_{4} f_{y}+\frac{E_{s}\left(1-k_{4}\right)}{\varepsilon_{y}\left(k_{2}-k_{1}\right)^{2}}\left(\varepsilon-k_{2} \varepsilon_{y}\right)^{2}, & \varepsilon>k_{1} \varepsilon_{y},\end{cases}
$$

where $k_{1}$ is the ratio of the initial strain of hardening steel to the yield strain, $k_{2}$ is the ratio of the peak strain of the steel bar to the yield strain, $k_{3}$ is the ratio of ultimate strain to yield strain of steel bars, and $k_{4}$ is the ratio of the peak stress of the steel bar to the yield strength, respectively.

4.2. Finite Element Models. The solid element C3D8R was applied to simulate the concrete, and the truss element T3D2 was concerned with steel bars. In the process of establishing the models, the assembled shear wall models of the two connection forms were properly simplified. Moreover, the structural glue and steel plate in PCW2 and cast-in-situ plug grouting in PCW3 were ignored, so that the interaction between components was definite.

The interaction between steel skeleton and concrete utilized the "embed region," which meant that there was almost no relative slippage between steel and concrete. The two surface types in precast shear walls were considered: one was the surface between the hidden column and wall, and the other was the surface between the upper or lower-half wall and top or bottom beam. Furthermore, the bonding operation was utilized on the above surface. It was noted that there was definitely slip but little normal strain in the surface between the upper and lower precast shear wall. Thus, the friction coefficient was set as 0.8 in PCW2 and 0.6 in PCW3. To guarantee the accuracy and convergence of the model, the dimension of the finite element was $50 \mathrm{~mm}$.

The boundary condition was to completely fix the foundations of the specimens. The vertical loads by applying uniform compression on the surface of the loading beam were adopted. And the horizontal load was applied in the form of displacement control, in which the left side of the loading beam was coupled to a point, and horizontal displacement was applied through the boundary created by the point. The loading condition was identical to the experimental condition.

4.3. Skeleton Curves of Simulation Results. Figure 11 shows the comparison of skeleton curves of PCW2 and PCW3 in experiments and numerical simulation. The simulated skeleton curves were generally consistent with experimental results, affecting the feature variation in different stages. However, the load capacity in the simulation was slightly larger than that in experiments. This was because the 


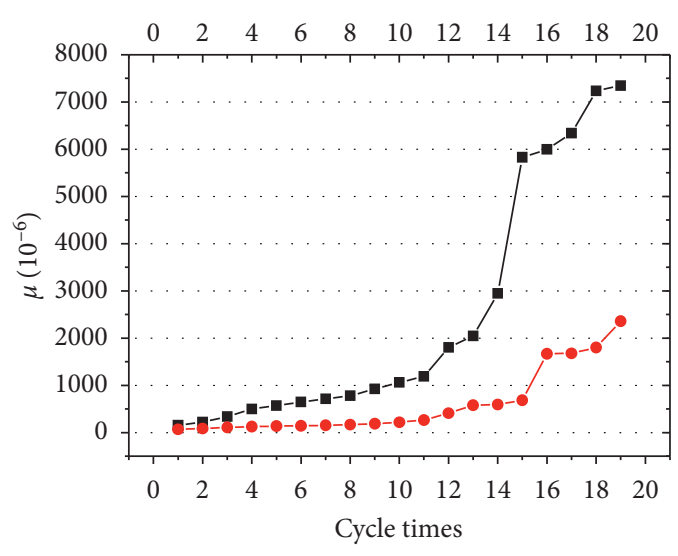

- - Vertical reinforcement in the bottom

- - Vertical reinforcement in the middle

(a)

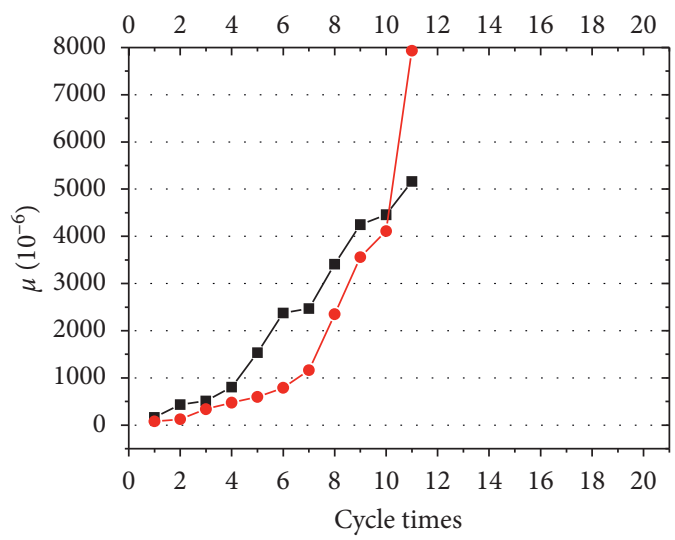

- - Vertical reinforcement in the bottom

- $\bullet$ Vertical reinforcement in the middle

(c)

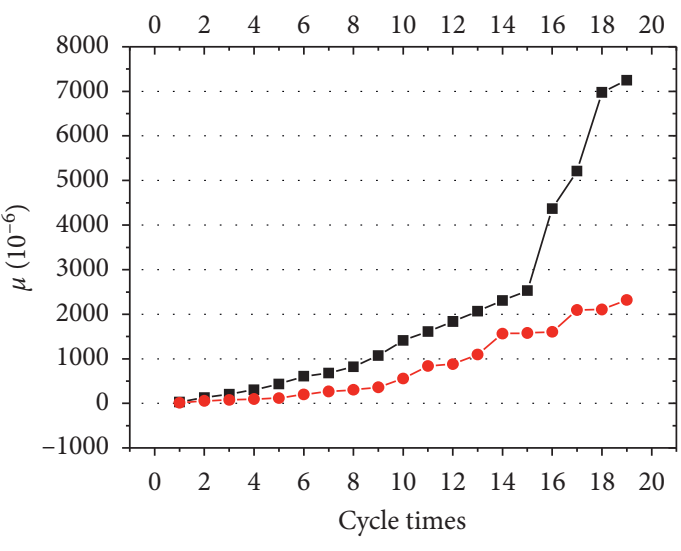

- - Vertical reinforcement in the bottom

-๑- Vertical reinforcement in the middle

(b)

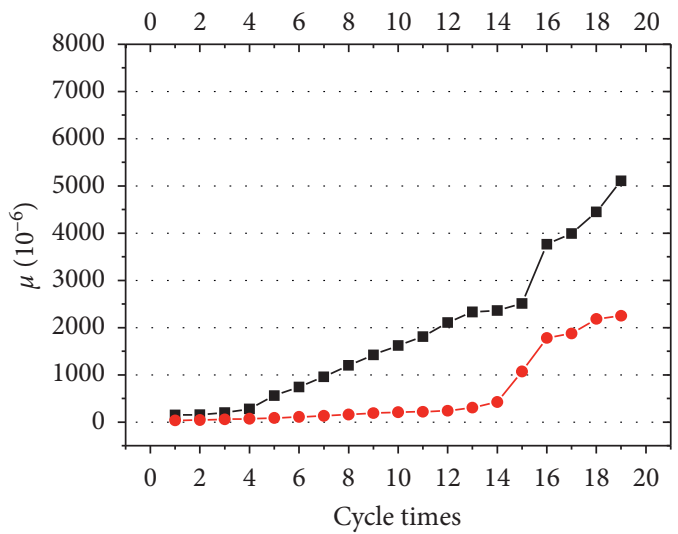

- - Vertical reinforcement in the bottom

- $\bullet$ Vertical reinforcement in the middle

(d)

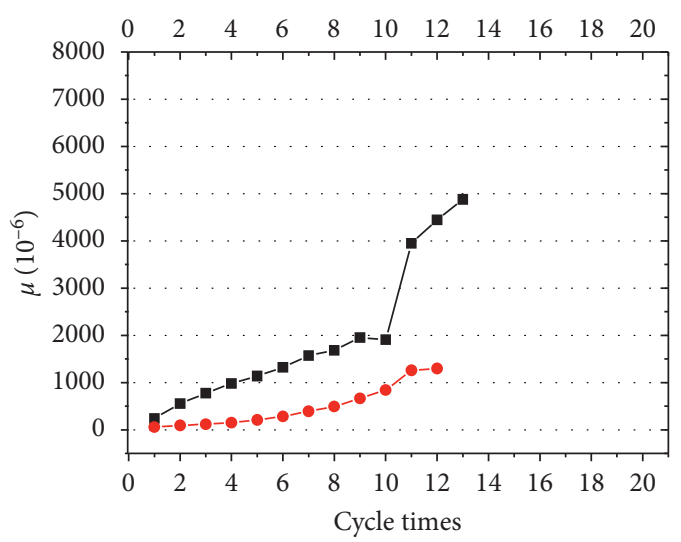

- - Vertical reinforcement in the bottom

-๑- Vertical reinforcement in the middle

(e)

FIGURE 9: Reinforcement strain of specimens. (a) RCW1. (b) RCW2. (c) PCW1. (d) PCW2. (e) PCW3. 


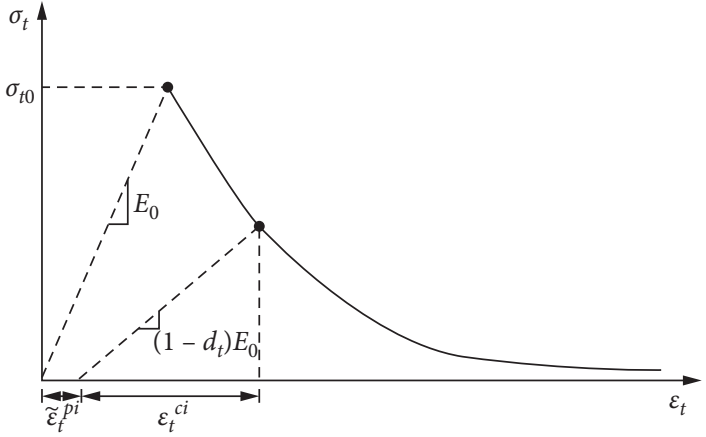

(a)

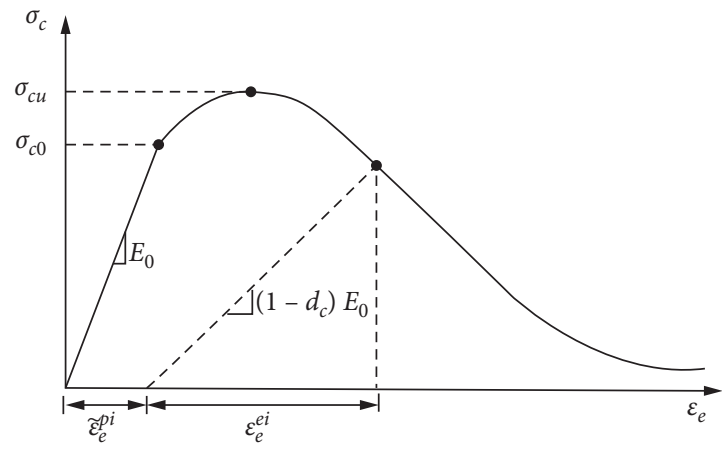

(b)

FiguRE 10: Response of concrete to uniaxial loading in tension (a) and compression (b). (Figure 10 is reproduced from Yilmaz et al. [29]).

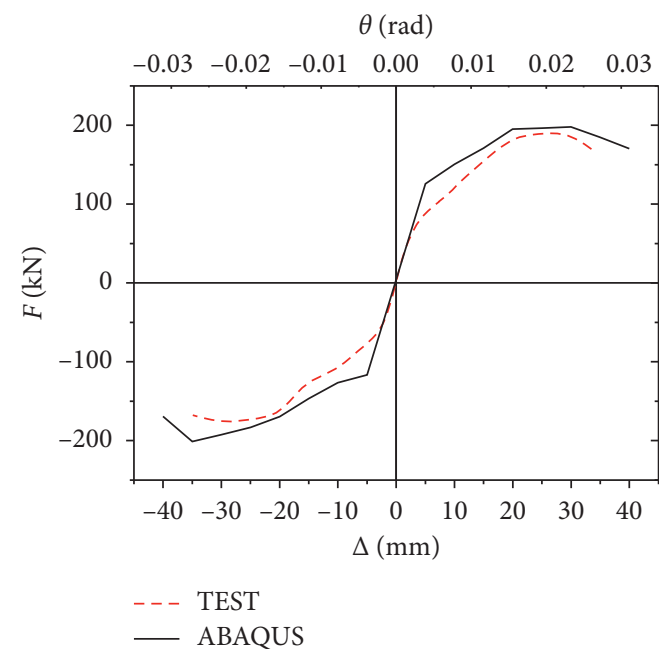

(a)

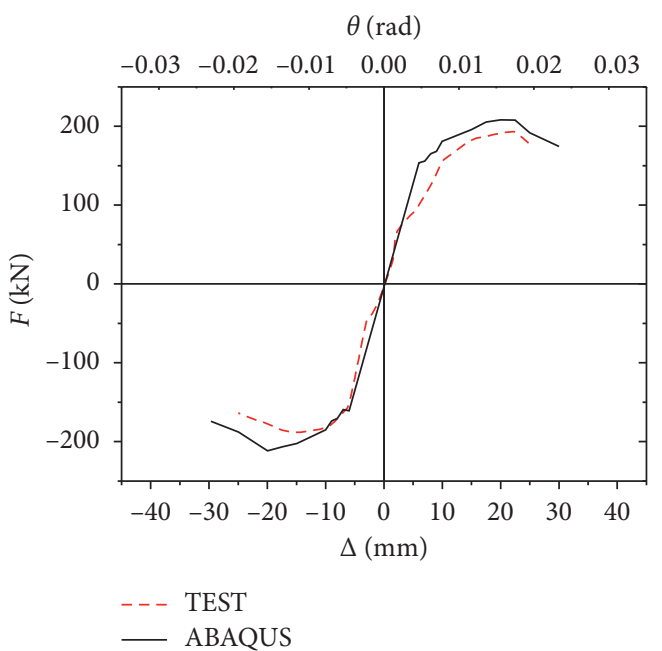

(b)

Figure 11: Comparison of skeleton curves in the test and numerical simulation. (a) PCW2. (b) PCW3.

TABLE 4: Characteristic point of the tests and simulations.

\begin{tabular}{|c|c|c|c|c|c|c|c|c|c|c|c|c|c|}
\hline \multirow{3}{*}{\multicolumn{2}{|c|}{ Characteristic point }} & \multicolumn{4}{|c|}{ Yielding point } & \multicolumn{4}{|c|}{ Peak point } & \multicolumn{4}{|c|}{ Ultimate point } \\
\hline & & \multicolumn{2}{|c|}{$\begin{array}{l}\text { Displacement } \\
\quad(\mathrm{mm})\end{array}$} & \multicolumn{2}{|c|}{ Load $(\mathrm{kN})$} & \multicolumn{2}{|c|}{$\begin{array}{l}\text { Displacement } \\
(\mathrm{mm})\end{array}$} & \multicolumn{2}{|c|}{ Load $(\mathrm{kN})$} & \multicolumn{2}{|c|}{$\begin{array}{l}\text { Displacement } \\
(\mathrm{mm})\end{array}$} & \multicolumn{2}{|c|}{ Load $(\mathrm{kN})$} \\
\hline & & + & - & + & - & + & - & + & - & + & - & + & - \\
\hline \multirow{3}{*}{ PCW2 } & Test & 14.9 & -15.2 & 163.6 & -165.4 & 29.6 & -29.7 & 191.3 & -177.8 & 34.6 & -34.9 & 162.4 & -151.3 \\
\hline & Simulation & 17.6 & -17.5 & 144.5 & -162.7 & 29.9 & -34.9 & 195.9 & -201.0 & 39.9 & -39.9 & 178.1 & -169.3 \\
\hline & Deviation (\%) & 18.1 & 15.1 & 11.6 & 1.6 & 1.1 & 17.5 & 2.4 & 13.0 & 15.3 & 14.3 & 9.6 & 11.8 \\
\hline \multirow{3}{*}{ PCW3 } & Test & 12.0 & -10.2 & 156.1 & -160.7 & 22.3 & -22.1 & 194.6 & -175.3 & 24.8 & -24.3 & 178.3 & -147.8 \\
\hline & Simulation & 10.4 & -10.1 & 182.1 & -185.1 & 22.5 & -19.9 & 207.7 & -209.5 & 29.9 & -29.6 & 174.5 & -174.1 \\
\hline & Deviation (\%) & 13.3 & 1.0 & 16.6 & 15.1 & 0.9 & 9.9 & 6.7 & 19.5 & 20.0 & 21.8 & 2.1 & 17.7 \\
\hline
\end{tabular}

concrete discreteness and the initial defect were not considered in the numeral simulation. The simulation results show that the finite element models were reliable.

4.4. Comparison of Characteristic Loads. As shown in Table 4, characteristic loads in the experiments and the simulation are compared, including yielding load, peak load, and ultimate load. However, there are two different factors in the numerical simulation and experimental condition: (1) the finite element models are established under the ideal condition; however, there are some initial defects and heterogeneous materials in reality; (2) the displacement control is the single loading program in the simulation. As shown in Table 4, there are some deviations between tests and simulations, and the maximum deviation is $21.8 \%$. 
However, the load deviation is slightly smaller than that of displacement, and the results of the characteristic points are consistent with the experimental results.

\section{Conclusion}

In this paper, the horizontal cyclic loading test on five shear wall specimens is performed, including two cast-in-place shear walls with construction joints at the bottom and the middle (RCW1 and RCW2) and three precast shear walls with the structural glue horizontal connection, the structural glue cogged connection, and the cast-in-situ plug grouting connection (PCW1, PCW2, and PCW3). Meanwhile, the results of finite element models of PCW2 and PCW3 are analyzed. The main conclusions are drawn as follows:

(1) The moment-shear failure is observed in RCW1, RCW2, PCW2, and PCW3, while the severe slippage failure is observed in PCW1. When the construction joint is changed from bottom to middle, the integrity of the bottom region can be enhanced by preventing cracks and relieving the damage for PCW2 and PCW3. It is noted that moment-shear failure mode and the weakest region (the bottom of the shear walls) can not be changed by changing the construction joint or connection type in precast shear walls.

(2) The connection of PCW1 (structural glue horizontal connection) hardly contributes to the capacity of bearing shear forces; then characteristic loads, displacements, and energy dissipation of PCW1 are obviously lower than those of other specimens.

(3) The hysteretic curves of specimens are an inverse $S$ shape and were approximately consistent. Except for PCW1 with the minimum characteristic bearing capacity, the skeleton curves of other specimens are similar. Due to the larger stiffness of PCW3, the load under the reverse loading condition is smaller than that under the forward loading at each stage.

(4) Compared with RCW1 and RCW2, the yielding load, the peak load, and the ultimate load can be increased by $0.7 \%, 1.9 \%$, and $1.6 \%$ by installing the construction joint in the middle of shear walls; particularly, the ductility is increased $9.6 \%$. Therefore, stalling the construction joint in the middle has certain benefits to the shear wall.

(5) Compared with RCW1, the yielding load, peak load, and ultimate load of PCW2 are reduced by $1.37 \%$, $5.3 \%$, and $5.3 \%$, but the ductility is increased by $9.6 \%$. The same outcome is obtained by PCW3. It indicates that the two connection methods (the structural glue cogged connection and cast-in-situ plug grouting connection) can result in a slight decrease of the bearing capacity but a significant increase in ductility.

(6) Except for PCW1, the stiffness degradation of specimens (RCW1, RCW2, PCW2, and PCW3) decreases with the increase of displacement, and the energy dissipation gradually increases. The test results indicate that the difference of stiffness degradation between RCW1, RCW2, PCW2, and PCW3 is negligible.

(7) The simulation results are in good agreement with the experimental results. It suggests that the finite element models are reliable and the entire experimental progress can be reflected by the finite element models.

\section{Data Availability}

The test data used to support the findings of this study are available from the corresponding author upon request.

\section{Conflicts of Interest}

The authors declare that they have no conflicts of interest.

\section{Acknowledgments}

This research project has been funded by the Natural Science Foundation of Jiangsu Education Department (Grant: 19kjb560023) and the Science and Technology Program of Suqian (Grant: Z2018216). The authors would like to acknowledge the support of the organizations for providing photographs and advice.

\section{References}

[1] E. Brunesi, S. Peloso, R. Pinho, and R. Nascimbene, "Cyclic tensile testing of a three-way panel connection for precast wall-slab-wall structures," Structural Concrete, vol. 20, no. 4, pp. 1307-1315, 2019.

[2] E. Brunesi and R. Nascimbene, "Experimental and numerical investigation of the seismic response of precast wall connections," Bulletin of Earthquake Engineering, vol. 15, no. 12, pp. 5511-5550, 2017.

[3] W. Han, Z. Zhao, J. Qian, Y. Zhang, and T. Ma, "Experimental seismic behavior of squat shear walls with precast concrete hollow moulds," Earthquake Engineering and Engineering Vibration, vol. 18, no. 4, pp. 871-886, 2019.

[4] D. C. Feng, Z. Wang, and G. Wu, "Progressive collapse performance analysis of precast reinforced concrete structures," The Structural Design of Tall and Special Buildings, vol. 28, no. 5, p. e1588, 2019.

[5] H. Liu, Q. Han, Y. Bai, C. Xu, and X. Du, "Connection performance of restrained deformed grouted sleeve splice," Advances in Structural Engineering, vol. 21, no. 3, pp. 488-499, 2018.

[6] M. Savoia, N. Buratti, and L. Vincenzi, "Damage and collapses in industrial precast buildings after the 2012 Emilia earthquake," Engineering Structures, vol. 137, pp. 162-180, 2017.

[7] J. Li, Q. Fan, Z. Lu, and Y. Wang, "Experimental study on seismic performance of T-shaped partly precast reinforced concrete shear wall with grouting sleeves," The Structural Design of Tall and Special Buildings, vol. 28, no. 13, p. e1632, 2019.

[8] J. Li, Y. Wang, Z. Lu, and J. Li, "Experimental study and numerical simulation of a laminated reinforced concrete shear wall with a vertical seam," Applied Sciences, vol. 7, no. 6, p. 629, 2017. 
[9] Z. Lu, X. Chen, X. Li, and P. Li, "Optimization and application of multiple tuned mass dampers in the vibration control of pedestrian bridges," Structural Engineering and Mechanics, vol. 62, no. 1, pp. 55-64, 2017.

[10] M. Chu, J. Liu, and Z. Sun, "Experimental study on mechanical behaviors of new shear walls built with precast concrete hollow moulds," European Journal of Environmental and Civil Engineering, vol. 23, no. 12, pp. 1424-1443, 2019.

[11] N. H. Hamid and J. B. Mander, "Lateral seismic performance of multipanel precast hollowcore walls," Journal of Structural Engineering, vol. 136, no. 7, pp. 795-804, 2010.

[12] N. H. Hamid and J. B. Mander, "A comparative seismic performance between precast hollow core walls and conventional walls using incremental dynamic analysis," Arabian Journal for Science and Engineering, vol. 37, no. 7, pp. 1801-1815, 2012.

[13] N. H. Hamid and J. B. Mander, "Damage avoidance design for buildings," KSCE Journal of Civil Engineering, vol. 18, no. 2, pp. 541-548, 2014.

[14] B. J. Smith, Y. C. Kurama, and M. J. McGinnis, "Behavior of precast concrete shear walls for seismic regions: comparison of hybrid and emulative specimens," Journal of Structural Engineering, vol. 139, no. 11, pp. 1917-1927, 2013.

[15] X. Zhai, X. Zhang, C. Cao, and W. Hu, "Study on seismic performance of precast fabricated RC shear wall with opening filling," Construction and Building Materials, vol. 214, pp. 539-556, 2019.

[16] X. Lu, L. Wang, D. Wang, and H. Jiang, "An innovative joint connecting beam for precast concrete shear wall structures," Structural Concrete, vol. 17, no. 6, pp. 972-986, 2016.

[17] G. Xu and A. Li, "Seismic performance of a new type precast concrete sandwich wall based on experimental and numerical investigation," Soil Dynamics and Earthquake Engineering, vol. 122, pp. 116-131, 2019.

[18] Q. Gu, G. Dong, X. Wang, H. Jiang, and S. Peng, "Research on pseudo-static cyclic tests of precast concrete shear walls with vertical rebar lapping in grout-filled constrained hole," Engineering Structures, vol. 189, pp. 396-410, 2019.

[19] J. H. Ling, A. B. A. Rahman, I. S. Ibrahim, and Z. A. Hamid, "An experimental study of welded bar sleeve wall panel connection under tensile, shear, and flexural loads," International Journal of Concrete Structures and Materials, vol. 11, no. 3, pp. 525-540, 2017.

[20] S.-M. Kang, O.-J. Kim, and H.-G. Park, "Cyclic loading test for emulative precast concrete walls with partially reduced rebar section," Engineering Structures, vol. 56, pp. 1645-1657, 2013.

[21] Housing and Urban-Rural Development of the People's Republic of China and General Administration of Quality Supervision, Inspection and Quarantine of the People's Republic of China, Standard for Test Method of Mechanical Properties on Ordinary Concrete, China Building Industry, Beijing, China, 2002.

[22] R. Park, M. J. N. Priestley, and W. D. Gill, "Ductility of squareconfined concrete columns," Journal of the Structural Division, vol. 108, no. 4, pp. 929-950, 1982.

[23] T. N. Salonikios, A. J. Kappos, I. A. Tegos, and G. G. Penelis, "Cyclic load behavior of low-slenderness reinforced concrete walls: failure modes, strength and deformation analysis, and design implications," ACI Structural Journal, vol. 97, no. 1, pp. 132-141, 2000.

[24] X. Tang, L. Liu, Z. Zhou, and L. Yang, "Experimental study on seismic behavior of slitted masonry in-filled reinforced concrete frame structure," Journal of Building Structures, vol. 10, 2012.
[25] Housing and Urban-Rural Development of the People's Republic of China and General Administration of Quality Supervision, Inspection and Quarantine of the People's Republic of China, Code for Seismic Design of Buildings, China Building Industry, Beijing, China, 2010.

[26] ACI Committee, Building Code Requirements for Structural Concrete (ACI 318-08) and Commentary, American Concrete Institute, Farmington Hills, MI, USA, 2008.

[27] X. Li, T. Zhou, J. Li, X.-B. Kuang, and Y.-W. Zhao, "Seismic behavior of encased CFT column base connections," Engineering Structures, vol. 182, no. 1, pp. 363-378, 2019.

[28] R. Park and T. Paulay, Reinforced Concrete Structures, John Wiley \& Sons, Hoboken, NJ, USA, 1975.

[29] T. Yilmaz, N. Kirac, O. Anil, R. T. Erdem, and C. Sezer, "Lowvelocity impact behaviour of two way RC slab strengthening with CFRP strips," Construction and Building Materials, vol. 186, no. 20, pp. 1046-1063, 2018. 